\title{
Intrapartum Amnioinfusion in Meconium Stained Amniotic Fluid: An Update
}

\author{
${ }^{1}$ Tamkin Khan Rabbani, ${ }^{2}$ Ayesha Ahmad \\ ${ }^{1}$ Reader, Department of Obstetrics and Gynecology, Jawaharlal Nehru Medical College, Aligarh Muslim University, Aligarh \\ Uttar Pradesh, India \\ ${ }^{2}$ Senior Resident, Department of Obstetrics and Gynecology, Jawaharlal Nehru Medical College, Aligarh Muslim University \\ Aligarh, Uttar Pradesh, India
}

Correspondence: Tamkin Khan Rabbani, Reader, Department of Obstetrics and Gynecology, Jawaharlal Nehru Medical College, Aligarh Muslim University, A-4, Medical Colony, Aligarh, Uttar Pradesh, India, Phone: 09412485219 e-mail: rabbanimuin@yahoo.co.uk

\section{Abstract}

The presence of meconium is associated with an increase in perinatal mortality and morbidity and remains a concern of both obstetricians and neonatologists. Approximately 8 to $16 \%$ of pregnancies may be complicated by the presence of meconium in amniotic fluid. In about one third cases, meconium may be present below vocal cords. This poses a risk of meconium aspiration syndrome, which carries a mortality rate as high as $25 \%$. Amnioinfusion is a procedure whereby a physiologic solution is infused into the uterine cavity to replace or dilute amniotic fluid. It has been found to relieve umbilical cord compression and dilute meconium, thus reducing the risk of meconium aspiration. Improved perinatal outcomes have been documented in different studies where intrapartum transcervical amnioinfusion was administered to women with meconium stained liquor. It remains a cheap, feasible and good alternative in low resource settings where facilities for electronic fetal monitoring are limited.
\end{abstract}

Keywords: Amnioinfusion, Meconium aspiration syndrome, Oligohydramnios, Meconium stained liquor.

The presence of meconium is associated with a higher incidence of abnormal labor, fetal distress, low apgar scores and delivery by cesarean section. ${ }^{1}$ It has been estimated that as many as 8 to $16 \%$ of pregnancies may be complicated by the presence of meconium in amniotic fluid. ${ }^{2}$ Meconium aspiration may occur antepartum or intrapartum. Meconium aspiration syndrome develops when there is mechanical obstruction and chemical inflammation as a result of aspiration of meconium into the lower respiratory tract of the fetus or neonate. It is a lifethreatening respiratory disorder, defined as respiratory distress in a neonate with meconium aspiration. It has been estimated to have a mortality rate of $25 \%$. Some studies have demonstrated that presence of thick rather than thin meconium in amniotic fluid is associated with adverse perinatal outcome. ${ }^{3,4}$ Various methods such as intrapartum amnioinfusion, splinting the chest of the baby till suctioning is started at birth and proper tracheoesophageal suctioning have been employed to decrease the risk of meconium aspiration.

Intrapartum amnioinfusion was initially proposed by Wenstrom and Parsons, as a method of diluting meconium to decrease the incidence of MAS. ${ }^{5}$ The instillation of normal saline into the uterus was theorized to reduce meconium concentration and thereby the effect of aspiration. Similar results have been recorded in other studies. ${ }^{6}$ It has also been observed that women with oligohydramnios have higher degree of meconium staining. This has been attributed to dilution of the same amount of meconium when liquor is normal, as a result of which meconium appears thin. Amnioinfusion may, therefore, not only dilute meconium but also correct oligohydramnios and, thus relieve umbilical cord compression.

Various techniques of amnioinfusion have been described. Studies done in resource limited settings have employed the use of nasogastric tube of FG 8 , inserted transcervically into the uterine cavity just above the head. $500 \mathrm{ml}$ of normal saline, brought to room temperature, is infused over 30 minutes, followed by a further $500 \mathrm{ml}$ at the rate of $3 \mathrm{ml} / \mathrm{min} .^{7,8}$ The use of a maximum one liter of saline has been generally considered in centers where continuous electronic fetal monitoring is not available. The women are monitored by fetal heart auscultation every 15 minutes and uterine activity is assessed every half hour by palpation.

Rathore AM et al found the cesarean section rate to be significantly lower in women administered amnioinfusion (21\%) as compared to the control group (36\%). Importantly the cesareans done for fetal distress were lower in the study group (12\%) as compared to control group (26\%). Amnioinfusion was associated with a significant decrease in the incidence of meconium at the vocal cords, improvement in one minute apgar scores, respiratory distress and fewer admissions to NICU as compared with the controls. ${ }^{9}$

A prospective observational study was conducted in the Department of Obstetrics and Gynecology, JN Medical College, AMU, between January and December 2009. The aim of the study was to study the effect of intrapartum intracervical amnioinfusion on the perinatal outcome. A total of 50 patients were recruited to the study. Inclusion criteria were a period of 
gestation of at least 37 weeks, single live fetus in cephalic presentation, no major medical or obstetric complications, no known fetal malformation and presence of moderate or thick meconium in amniotic fluid. We found that $12 \%(6 / 50)$ of babies with MSAF had MAS. This is consistent with the incidence reported in many earlier studies. (Narang et al $10.5 \%$, Patil et al $12 \%) .{ }^{10,11} \mathrm{~A}$ higher incidence has been reported by Bhide et al $(22 \%)$ and Gregory et al $(20 \%) .{ }^{12,13}$ The cesarean section rate of $24 \%(12 / 50)$ is also consistent with other studies.

In a review of 186 academic departments in the United States in which 22,000 amnioinfusions were performed, 49 centers reported complications, including uterine hypertonia, fetal heart rate abnormality, precipitate labor, uterine rupture and maternal cardiac or pulmonary failure. Several case reports have been published of cardiac failure and amniotic fluid embolism resulting in maternal mortality. Although a causal relationship has not yet been established, it has been hypothesized that excessive uterine activity may be related to extra-amniotic placement of amnioinfusion catheter, resulting in stimulation of prostaglandin release. The trials, however, are too small to address the seriousness of maternal side effects of amnioinfusion. The benefits of amnioinfusion need to be weighed against the small theoretical risk of serious maternal complications. ${ }^{14-16}$

To assess the effects of amnioinfusion for meconium-stained liquor on perinatal outcome, the cochrane pregnancy and childbirth group's trials register (May 2009) was searched in a meta-analysis. Randomized trials comparing amnioinfusion with no amnioinfusion for women in labor with moderate or thick meconium-staining of the amniotic fluid were analyzed. Thirteen studies of variable quality consisting of 4143 women were included. Subgroup analysis was performed for studies from settings with limited facilities to monitor the baby's condition during labor and intervene effectively, and settings with standard peripartum surveillance. ${ }^{17}$ In settings with standard peripartum surveillance, there was no significant reduction in the primary outcomes meconium aspiration syndrome, perinatal death or severe morbidity, and maternal death or severe morbidity. There was a reduction in cesarean sections for fetal distress but not overall. Meconium below the vocal cords diagnosed by laryngoscopy was reduced, as was neonatal ventilation or neonatal intensive care unit admission, but there was no significant reduction in perinatal deaths or other morbidity. Planned sensitivity analysis excluding trials with greater risk of bias resulted in an absence of benefits for any of the outcomes studied.

In settings with limited peripartum surveillance, there were two studies in which 855 women were included. In the amnioinfusion group, there was a reduction in CS for fetal distress and overall. Meconium aspiration syndrome (RR 0.25, $95 \%$ CI 0.13 to 0.47 ), and neonatal ventilation or neonatal intensive care unit admission, and a trend towards reduced perinatal mortality (RR $0.37,95 \%$ CI 0.13 to 1.01 ). In one of the studies, meconium below the vocal cords was reduced and, in the other, neonatal encephalopathy was reduced. It was concluded that amnioinfusion is associated with substantive improvements in perinatal outcome only in settings where facilities for perinatal surveillance are limited. It is not clear, whether the benefits are due to dilution of meconium or relief of oligohydramnios. In settings with standard peripartum surveillance, some non-substantive outcomes were improved in the initial analysis, but sensitivity analysis excluding trials with greater risk of bias eliminated these differences. Amnioinfusion is either ineffective in this setting or its effects are masked by other strategies to optimize neonatal outcome. The authors concluded that the trials reviewed are too small to address the possibility of rare but serious maternal adverse effects of amnioinfusion. ${ }^{17}$

We conclude that a carefully performed amnioinfusion is a cheap, feasible and good alternative in low resource settings where facilities for electronic fetal monitoring are not available. It is associated with improvement in perinatal outcome as judged by improved apgar scores and decrease in perinatal mortality. There is a decrease in cesarean section rate.

\section{REFERENCES}

1. Katz VL, Bowes WA. Meconium aspiration syndrome: Reflections on a murky subject. Am J Obstet Gynecol 1992;166:171-83.

2. Woods JR, Glantz JC. Significance of amniotic fluid meconium. In: Creasy RK, Resnick R (Eds). Maternal fetal medicine: Principles and practice (3rd ed). Philadelphia: WB Saunders 1994;413-22.

3. Mahomed K, Nyoni R, Masona D. Meconium-staining of the liquor in a low-risk population. Pediatric Perinat Epidem 1994;8:292-300.

4. Ziadeh SM, Sunna E. Obstetric and perinatal outcomes of pregnancies with term labor and meconium-stained amniotic fluid. Arch Gynecol Obstet 2000;264:84-87.

5. Wenstrom KD, Andrews WW, Maher JE. Prevalence, protocols and complications associated with amnioinfusion. Am J Obstet Gynecol 1994;170:341.

6. Hofmeyr GJ. Amnioinfusion for meconium stained liquor in labor. In: Cochrane library issue 1. Oxford: Update software, 1999.

7. Hofmeyr G, Gulmezoglu AM, Buchmann E, et al. The collaborative randomized amnioinfusion for meconium project (CRAMP): 1 South Africa. BJOG 1998;105:304-08.

8. Mahomed K, Mulambo T, Woelk G, Gulmezoglu AM. The Collaborative randomized amnioinfusion for meconium project (CRAMP): 2 Zimbabwe. BJOG 1998;105:309-13.

9. Rathore AM, Singh R, Ramji S, et al. Randomized trial of aminioinfusion during labor with meconium stained amniotic fluid. BJOG 2002;109:17-20.

10. Narang A, Nari PMC, Bhakoo ON, et al. Management of meconium stained amniotic fluid: A team approach. Indian Pediatrics 1989;30:9-13. 
11. Patil KP, Swamy MK, Samatha K. A one year cross sectional study of management practices of meconium stained amniotic fluid and perinatal outcome. J Obstet Gynecol India 2006;56(2):128-30.

12. Bhide SS, Shendurnikar N, Aiyer S, et al. Neonatal outcome after meconium stained amniotic fluid. J Obstet Gynecol India 1994;48:933-34.

13. Gregory GA, Gooding CA, Phibbs RH, et al. Meconium aspiration in infants: A prospective study. J Pediatr 1974;85: 848-52.
14. Marci CJ, Schrimmer DB, Leung A, et al. Prophylactic amnioinfusion improves outcome of pregnancy complicated by thick meconium and oligohydramnios. Am J Obstet Gynecol 1992;167:117-21.

15. Uhing MR, Bhat R, Philobos M, et al. Value of amnioinfusion in reducing meconium aspiration syndrome. Am J Perinatol 1993;167:117-21.

16. Maher JE, Wenstrom KD, Hanth JC, et al. Amniotic fluid embolism after saline amnioinfusion: Two cases and review of literature. Obstet Gynecol 1994;83:851.

17. Hofmeyr GJ, Xu H. Amnioinfusion for meconium-stained liquor in labor. Cochrane database of systematic reviews 2010, Issue 1. 